\title{
AUTENTICIDADE, PRESENÇA E FABULAÇÃO NA ILUSTRAÇÃO E NOS QUADRINHOS DOCUMENTAIS*
}

Felipe de Castro Muanis**

Resumo: Analisando o trabalho de ilustradores e pintores como George Cruikshank (1782-1878) e Constantin Guys (1802-1892), este artigo discute a tradição da ilustração documental nos séculos XVIII e XIX. Tais autores ensaiavam, em suas práticas, características que se tornariam caras e comuns nos tensionamentos de discursos documentais contemporâneos no audiovisual e nas histórias em quadrinhos, como a presença, a fabulação e a autenticidade. Autores como Charles Baudelaire (1821-1867), Peter Burke (1937-) e Antoine Compagnon (1950-) serão trabalhados.

Palavras-chave: Ilustração. Fabulação. Presença.

\section{INTRODUÇÃo}

O s discursos que privilegiam uma representação do real ou uma pretensa exposição da verdade tornaram-se cada vez mais frequentes nos últimos 100 anos, tornando-se complexos nas formas, deslizando entre diversas mídias e aprofundando discussões éticas não apenas sobre seu fazer, como também sobre seus limites. Nesse cenário, os discursos documentais são tratados de maneiras distintas por seus próprios realizadores no cinema, na televisão ou nas histórias em quadrinhos. Enquanto o cinedocumentário, especialmente a partir da década de 1960, reage contra o modelo expositivo de Grierson por meio do cinema observacional e direto, a televisão absorve estratégias de diferentes modelos tanto do documentário quanto da ficção para construir seus relatos jornalísticos. Empacotado em formatos regulares condi-

\footnotetext{
Uma versão preliminar deste artigo foi apresentado na XXVI Compós, em 2017, realizada na Fundação Cásper Líbero, em São Paulo.

** Universidade Federal de Juiz de Fora (UFJF), Juiz de Fora, MG, Brasil; Universidade Federal do Ceará (UFC), Fortaleza, CE, Brasil. E-mail: muanis@mac.com
} 
zentes com a velocidade de produção e a exibição de seus conteúdos, o discurso telejornalístico é sempre colocado sob suspeita por estar subordinado a interesses empresariais e politicos que ficcionalizariam os relatos, afastando-se da realidade. Assim, o espaço das imagens audiovisuais para a representação do real, especialmente na televisão, caracteriza-se mais pela suspeita do que pela confirmação do que é exibido.

Outra mídia que dialoga com esse tipo de relato são as histórias em quadrinhos, que, especialmente a partir da década de 1960, também começaram a popularizar discursos documentais em que o homem comum e personagens reais são retratados, seja em histórias banais e autobiográficas de cotidiano (Pekar, Crumb), seja em relatos históricos e jornalísticos de guerras e conflitos (Spiegelman, Sacco). Comparada ao cinema, a discussão ética nos quadrinhos parece menos presente, muito pelo fato de os desenhos não serem considerados por várias pessoas uma ferramenta adequada de comprovação do real. Além disso, haveria o problema de sua própria mídia, ainda hoje percebida apenas como uma forma menor de entretenimento, direcionada prioritariamente para as crianças e os jovens. Contudo, pode-se pensar que os discursos do real do cinema, da televisão e dos quadrinhos têm uma origem comum, na qual se ensaia uma série de práticas similares e que hoje são problematizadas pelo documentário. É tanto na pintura quanto na ilustração editorial dos séculos XVIII e XIX, quando a fotografia ainda não tinha surgido e, consequentemente, empurrado o desenho para um espaço periférico da representação e de ornamento, que se podem observar relatos documentais de cotidiano e características que envolvem presentificação, fabulação e narrativização de eventos reais.

O objetivo deste artigo é discutir as práticas de alguns autores ingleses e franceses desse período, considerados, ainda hoje, precursores dos quadrinhos na ilustração documental editorial. Tais métodos, já naquela época, demonstravam como o fazer documental recorria a determinadas práticas constantes que, em vez de opostas, eram complementares, e ofereciam assim, uma perspectiva mais ampla de discursos válidos. É importante reforçar, no entanto, que se discute o real aqui como proximidade com os acontecimentos e como um valor intrínseco ao discurso documental em suas diversas manifestações. Parte-se do princípio de que toda representação de real é subjetiva, e uma hipotética pureza de real é impossivel de alcançar em qualquer discurso ou representação.

\section{Cruikshank, GuYs e o frenesi do visível}

De fato, os relatos gráficos documentais não se iniciam nas ilustrações europeias do século XVIII. Há inúmeras outras experiências de pinturas e ilustração em outros países que dialogam com a mesma lógica de representação. Um exemplo são as gravuras ou xilogravuras com representação do cotidiano japonês no período Edo ${ }^{1}$, chamadas de Ukiyo-e, a partir do século XVII, que representavam cenas de luta, do teatro, de acontecimentos históricos, da prostituição, entre outras. Da mesma forma, outras representações de cotidiano ainda mais antigas em pinturas, tapeçarias, tumbas egipcias, e mesmo nas pinturas rupestres nas cavernas, evidenciam um interesse constante do ser humano em represen-

\footnotetext{
Xogunato da família Tokugawa entre 1603 e 1868.
} 
tar sua realidade ou seus próprios acontecimentos. Esses relatos e essas representações ganham outra dimensão com a invenção da imprensa e a editoração de jornais por diversos países da Europa no século XVII, onde as ilustrações começariam a deixar espaços reservados sacralizados ou as casas de mecenas abastados para serem difundidas em folhetins acessiveis e de baixo custo, o que muda a própria noção de público e do adereçamento das ilustrações. Jean Louis Comolli (1980, p. 122, tradução nossa), no texto Machines of the visible, lembra que: "A segunda metade do século XIX viveu uma espécie de frenesi do visivel. Isso é, claro, o efeito da multiplicação social das imagens: cada vez maior distribuição de jornais ilustrados, modos de impressão, caricaturas etc.”.

Influenciado pelas pinturas e gravuras satíricas de William Hogarth (16971764), que, por sua vez, influenciou uma série de caricaturistas e ilustradores entre os séculos XVIII e XX, James Gillray (1756-1810) se notabilizou, no fim do século XVIII, por cartuns inspirados por acontecimentos politicos e charges sociais que retratavam o cotidiano. Por esse motivo, suas ilustrações são consideradas ainda hoje documentos fidedignos de hábitos e debates políticos daquele tempo. É importante ressaltar, contudo, a pertinente observação de Peter Burke (2004, p. 180), de que imagens produzidas em temporalidades diferentes de seus espectadores criam problemas, na medida em que "as convenções narrativas ou discurso" são distintos nas duas épocas, dificultando a leitura e compreensão ${ }^{2}$. Ainda assim, pode se dizer que as ilustrações de Gillray eram imagens únicas que muitas vezes já utilizavam os populares balões das histórias em quadrinhos contemporâneas para aliar diálogos às imagens. Apesar de suas ilustrações serem únicas e não sequenciais, ficam evidentes as características narrativas de representação de cotidiano, bem como representações simbólicas, nas quais Gillray buscava traduzir sua interpretação subjetiva dos fatos, muitas vezes deturpando intencionalmente a realidade. Tinha como alvos principais de suas críticas o rei George III e Napoleão, mas apontava suas sátiras para diversos políticos, independentemente de viés ideológico. A força do trabalho de Gillray foi uma influência decisiva na ilustração de George Cruikshank na Inglaterra do século XIX e permanece até hoje: Gillray foi apontado pelo quadrinista Joe Sacco (1960-), autor de reportagens em quadrinhos como Palestina (1996), Área de segurança Gorazde (2000) e Notas sobre Gaza (2010), como uma de suas principais influências pelo caráter descritivo e de reportagem de suas ilustrações.

É no trabalho de George Cruikshank que se percebem algumas indicações dos dilemas presentes no discurso gráfico documental. Ainda que seu nome talvez seja mais conhecido por ter sido ilustrador de livros de Charles Dickens (1812-1870) - e, inclusive, por reivindicar para si a coautoria de Oliver Twist -, Cruikshank sucedeu Hogarth e Gillray e passou a ser considerado o ilustrador mais popular da Inglaterra. Assim como Gillray, seu trabalho ultrapassou as fronteiras do Reino Unido e se espalhou por toda a Europa. Suas ilustrações tinham em comum a presença da figura humana, sempre evidente como um elemento importante e central em seu trabalho. No trabalho de Cruikshank é dificil ver naturezas mortas ou paisagens em que o ser humano não apareça como um agente do espaço cênico. Seu interesse pelo cotidiano e pelo homem banal se evidencia em diferentes edições.

2 Burke dá o exemplo de sentidos distintos de leitura, da direita para esquerda, de figuras representadas mais de uma vez na mesma cena, poses e outras características. 
De acordo com Hillary Evans (1978, p. 7-11), a ilustração de George Cruikshank apresentava três mundos distintos e complementares que lidam de forma totalmente distinta com o real: o mundo como ele é, o mundo idealizado e o mundo da fantasia. O mundo como ele é representa o tema da vida mundana desperdiçada em bares e pubs, a violência da máfia e das autoridades e o mundo das rebeliões em Paris e na Irlanda. É o mundo que o ilustrador, adepto da responsabilidade social e que se tornou cada vez mais conservador, apesar de desconfiar da Igreja, retratava com desaprovação. Com uma crença profunda na humanidade, Cruikshank não reproduzia vilões explícitos, pois entendia que o ser humano nunca era essencialmente mau e que, se assim o fosse, seria apenas por influência de seu entorno. Para mudá-lo, então, segundo ele, era necessário mudar o mundo (EVANS, 1978, p. 11). Contrapondo a essa visão realista, mas benevolente, do inglês do século XIX, Cruikshank também idealizava o mundo de acordo com sua concepção. Nessas ilustrações idílicas, o ilustrador representava a vida como deveria ser: crianças felizes e suas famílias brincando alegremente no campo, as festas populares e os teatros com pessoas felizes e animadas. Por fim, o terceiro mundo de Cruikshank era o da fantasia e do escape, em que personagens de fábula provenientes do universo dos contos de fadas povoavam a imaginação. Porém, em seu mundo da fantasia, bruxas, príncipes, fadas e monstros eram mais piedosos, em vez de odiarem ou sentirem medo. Esses três mundos demonstram claramente uma idealização da realidade por parte do autor, pois, mesmo quando retratava o mundo como ele é, abdicava da maldade do ser humano, abrindo mão deste como agente das transformações e dos hábitos negativos e posicionando-o como vítima do mundo. Conclui-se, portanto, que Cruikshank evidenciava claramente sua subjetividade na constituição da realidade, mesmo quando buscava representar o mundo tal como era, com maior objetividade.

De sua vasta produção de quase - e surpreendentes -10 mil ilustrações, destacam-se três edições de interesse da pesquisa que ora se apresenta. Em 1820, Cruikshank e seu irmão ${ }^{3}$ publicaram Life in London (1820) em 20 edições mensais, obtendo grande sucesso. A publicação retratava cenas populares da vida cotidiana londrina - que ambos conheciam por morarem em Londres -, resultando em um trabalho bastante fidedigno dos hábitos e costumes locais nos cafés, nas tavernas, mesas de jogo, nas ruas e na polícia. De acordo com Hillary Evans (1978, p. 44, tradução nossa), “[...] suas ilustrações retratavam cada cena em detalhes vividos que só poderiam ser fruto de uma observação local. Tudo isso adicionava um panorama singular de Londres". Com o sucesso de Life in London, dois anos depois, em 1822, Cruikshank publica Life in Paris, dessa vez sem a participação do irmão, com a mesma proposta, retratando o cotidiano de Paris. Há, contudo, uma diferença crucial desta para a primeira experiência: Cruikshank não conhecia Paris e baseou suas ilustrações nos relatos e nas referências visuais de amigos e pessoas que conheciam a capital francesa. Desse modo, combinou relatos e imaginação para retratar o cotidiano da cidade. Apesar dessa limitação, a publicação teve ótima aceitação do público, alcançando boa vendagem.

Naturalmente, a discussão que se impõe aqui é a questão da presença e da fabulação do ilustrador, tão caras às discussões, por exemplo, no cinedocumen-

3 George Cruikshank foi o mais importante de uma linhagem de ilustradores, que incluem seu pai e seus irmãos. 
tário. Qual a validade de um discurso que pretende refletir o real na medida em que não se está presente ou não se conhece de fato a realidade que irá representar? O sucesso de Life in Paris demonstra que Cruikshank alcançou, por meio de depoimentos, testemunhos e referências indiretas, alguma fidedignidade com a realidade retratada. Pode-se, então, fazer a pergunta de outro modo: até que ponto a presença é fundamental como atestado de autenticidade em um discurso de real? Não se está colocando em questão aqui, por enquanto, outro fator comum em uma discussão com esse tipo de objeto de análise, que é a validade do desenho como instrumento de representação do real, o que será discutido mais à frente. De qualquer maneira, testemunhos e depoimentos sobre um acontecimento, sem uma necessária presença do realizador, são frequentes no cinedocumentário e no telejornalismo, que, embora também sejam postos sob suspeição, não perdem seu caráter de representação do real.

A terceira obra de Cruikshank é o Comic almanack (1835-1853), publicado com sucesso, mensalmente, por 19 anos. Ao contrário das obras anteriores, feitas sob encomenda, essa era uma publicação idealizada pelo próprio ilustrador e que, por isso, gozava de autonomia para seus cartuns. Nela, o ilustrador representava sua visão de mundo, a maneira de perceber as coisas e até hoje, por tratar de assuntos muito particulares e específicos dos momentos da época, constitui um importante documento de hábitos, costumes, vestuário e caracterização do período. De acordo com Evans (1978), o texto em si é quase incompreensível atualmente pela ligação muito próxima com acontecimentos da época, e são justamente os desenhos que sobressaem. Pode-se dizer, assim, que Cruikshank trabalhava em diferentes aspectos do registro documental, seja com fontes e fabulação do real, seja, de outro modo, como testemunha do espaço retratado. Também detalhava a vida cotidiana e priorizava o homem comum, alternando de representações do cotidiano para representações simbólicas em que buscava ou uma sintese da realidade pela junção de fontes secundárias de informação, ou uma idealização da realidade por um mundo idílico ou fantasioso.

Ao mesmo tempo que Gillray e Cruikshank publicavam suas charges e cartuns na Inglaterra e fora dela, na França outros ilustradores cumpriam papel semelhante, com destaque para Honoré Daumier (1808-1879) e Constantin Guys (1802-1892), não por acaso ambos citados por Charles Baudelaire em Le peintre de la vie moderne (1863), com destaque para Guys e o potencial de suas ilustrações como registro da vida nas grandes cidades e nas áreas de conflito, especialmente as representações da Guerra da Crimeia.

O aspecto principal das ilustrações de Honoré Daumier é a crítica social e política, especialmente nas páginas das revistas como La Caricature (1830-1843) e depois da revista Le Charivari (1832-1937), fundada por ele. Suas ilustrações e pinturas retratavam pobreza, miséria e o homem comum, mas fazia mais sucesso fora da França, especialmente com colecionadores da Inglaterra e da Alemanha. De acordo com Ada Ackerman (2014), o público francês o considerava moderado, e não alguém socialmente engajado e combativo, como era percebido pelos soviéticos na década de 1930. Em Eisenstein et Daumier: des affinités électives, Ackerman (2014) reforça a influência do trabalho de Daumier na Rússia como representação do real e do homem comum, explicitando especialmente suas influências no trabalho do cineasta Sergei Eisenstein (1898-1948). De fato, a comparação das fisionomias, por vezes caricatas, além de gestos, vestuários e hábitos nas ilustrações de Daumier, encontra paralelo em planos em close de 
diversos filmes de Eisenstein, definindo status sociais e morais, delimitação de tipos populares como partisans, em contraponto com figuras grotescas, como opositores da revolução, conforme afirma Ackerman. É possivel ainda encontrar na ilustração de Daumier as mesmas figuras populares em posturas imponentes e quase heroicas, reproduzidas à exaustão pela arte dos cartazes construtivistas russos. Todavia, se essa idealização do popular e do homem comum fica evidente na iconografia soviética, é importante ressaltar que Honoré Daumier buscava a integridade desses personagens, mas não escondia sua pobreza e infortúnio, especialmente em suas pinturas. Em função dessa representação das pessoas retratadas, as ilustrações de Daumier são consideradas um trabalho jornalístico ou, como recomendou Charles Baudelaire (apud ACKERMAN, 2014, p. 119), "[...] folheiem sua obra e verão desfilar diante de seus olhos a realidade fantástica e impressionante, tudo o que uma grande cidade contém de monstruosidades vivas".

Mas a admiração de Baudelaire pela ilustração se tornou mais explícita com Constantin Guys, ou G., por meio da análise que faz de seu trabalho em Le peintre de la vie moderne (1863). Baudelaire entendia a modernidade como o que extrai o eterno do transitório, do efêmero e do incerto. Para o poeta, a beleza não se encontrava apenas nos museus e nas obras dos pintores das coisas eternas e dos grandes temas heroicos e religiosos que constituiriam a alma da arte, mas na banalidade da vida comum e do cotidiano, das circunstâncias, do variável, que, por sua vez, se constituiria no corpo da arte. Como descreve Antoine Compagnon (2003, p. 24), "Baudelaire vê em Guys a combinação ideal do instante e da totalidade, do movimento e da forma, da modernidade e da memória" em que o sentido do presente se sobrepõe e apaga tanto o passado quanto o futuro. Baudelaire entendia Guys como um homem do mundo, em oposição ao artista que busca entender o mundo e seus hábitos, ou seja, por meio de suas ilustrações, Guys era um privilegiado observador da modernidade, testemunha do presente, definidor da modernidade que nega o passado:

Podemos apostar com toda certeza que, dentro de alguns anos, os desenhos de G. se tornarão arquivos preciosos da vida civilizada. Suas obras serão procuradas pelos curiosos tanto quanto as dos Debucourt, dos Moreau, dos Saint-Aubin, dos Carle Vernet, dos Lami, dos Devéria, dos Gavarni, e de todos esses artistas excelentes que, por terem pintado somente o familiar e o belo, não deixam de ser, a seu modo, sérios historiadores. Vários deles fizeram inclusive muitas concessões ao belo e introduziram algumas vezes em suas composições um estilo clássico alheio ao tema; vários arredondaram voluntariamente os ângulos, aplainaram as asperezas da vida, amorteceram-lhe as fulgurantes explosões. Menos hábil do que estes, G. tem um mérito profundo que lhe é peculiar; desempenhou voluntariamente uma função que outros artistas desdenharam e que cabia sobretudo a um homem do mundo preencher. Ele buscou por toda a parte a beleza passageira e fugaz da vida presente, o caráter daquilo que o leitor nos permitiu chamar de Modernidade. Frequentemente estranho, violento e excessivo, mas sempre poético, ele soube concentrar em seus desenhos o sabor amargo ou capitoso do vinho da vida (BAUDELAIRE, 1996, p. 69).

Constantin Guys ilustrava para jornais britânicos e franceses e foi correspondente jornalístico notadamente para regiões em conflito, como a Guerra da 
Crimeia ${ }^{4}$. Essa não é uma característica exclusiva de Guys: segundo Burke, outros artistas, como os flamengos Jan Vermeyen (1500-1559) e Adam van der Meulen (1632-1690), o francês Louis-François Lejeune (1775-1848) e o suíço Niklaus Manuel Deutsch (1484-1530) - este ainda no século XVI -, tinham a prática de viajar, atuando como militares ou como correspondentes jornalísticos, e ilustrar o próprio testemunho por meio da pintura ou esboços de batalhas.

A presença do artista no local e como testemunha do fato, além da prática do jornalismo, da apuração no espaço, era feita da mesma maneira como faz atualmente, por exemplo, o quadrinista Joe Sacco ${ }^{5}$. Baudelaire afirma que os desenhos de Constantin Guys são documentos de uma época, de modernidade, e não deixam nada a dever aos relatos de historiadores. Nesse sentido, contudo, Burke lembra uma crítica pertinente do pintor Horace Vernet ${ }^{6}$ (1789-1863) que pode ser associada ao trabalho jornalístico de Guys e que também põe em xeque essa presença:

[...] ele realmente observa um problema recorrente do gênero. A dificuldade de se observar um combate de uma pequena distância e o desejo de produzir imagens heróicas estimulou o uso de figuras típicas, fórmulas tiradas da escultura clássica (BURKE, 2004, p. 183).

Essa postura heroica deixará de existir posteriormente para dar espaço a um estilo anti-heroico ou real, conforme Burke - sem contudo precisar uma data precisa para essa transformação. As tragédias da guerra mostrando o lado dos perdedores ou as "cenas das batalhas sem herói” (BURKE, 2004, p. 187) marcam o que o autor chama de uma "contra-ofensiva visual". É essa transformação para o estilo anti-heróico que foi assimilada pela pintura ${ }^{7}$, pela ilustração editorial e, posteriormente, pelos quadrinhos contemporâneos de conflito, em especial de Joe Sacco - que por sua vez dialoga com o quadrinho underground anti-heroico, ordinário e realista da década de 1960. Mais do que isso, é importante sempre pensar o que está por trás dessas escolhas:

No caso da pintura de batalha heróica, as pressões dos que encomendam, frequentemente príncipes ou generais - precisam ser lembradas, ao passo que no caso da fotografia anti-heróica, o historiador não pode se dar ao luxo de esquecer as pressões de editores de jornais e estações de televisão, preocupados com histórias que tenham "interesse humano". Mesmo assim, imagens frequentemente revelam detalhes significativos que reportagens verbais omitem. Elas oferecem aos espectadores distanciados no espaço ou no tempo algum senso da experiência de batalha em diferentes periodos. Elas também atestam de forma nítida as mudanças das atitudes em relação à guerra (BURKE, 2004, p. 189).

4 Burke (2004, p. 186) ressalta ainda que para a guerra da Crimeia foram inúmeros artistas britânicos para fazer o mesmo que Guys, entre eles Edward Armitage (1817-1896), Joseph Crowe, Edward Goodall (1795-1870) e William Simpson (1823-1899).

5 Joe Sacco visitou o lugar retratado durante alguns meses, depois retornou aos Estados Unidos, onde produziu suas histórias em quadrinhos durante dois ou três anos.

6 De acordo com Burke (2004, p. 183), Vernet fora criticado por Baudelaire justamente "por produzir cenas de batalha 'que consistiam apenas uma gama de pequenas anedotas interessantes'".

7 Em Los desastres de la Guerra (1810-1820), Francisco de Goya (1746-1828) inspirou-se em Les Grandes Misères et les Malheurs de la Guerre (1633), de Jacques Callot (1592-1635). Ambos os artistas são considerados por Hillary Chute (2016, p. 40) os fundadores dos artistas-repórteres. Goya, por sua vez, é apontado pela autora como influência fundamental tanto do quadrinho underground como de seu principal artista, Robert Crumb (1943-), assim como de Art Spiegelman (1948-), Joe Sacco (1960-) e Keiji Nakazawa (1939-2012). 
O aspecto da presença, desse modo, é essencial para a discussão que se segue. Poder-se-ia, portanto, fazer uma comparação entre as estratégias de Cruikshank, especialmente de Life in Paris, em que as ilustrações foram feitas a partir de relatos de outros testemunhos, em contraste com as ilustrações de Guys, que de fato foi aos locais retratados, ainda que sofresse das limitações apontadas por Burke e Vernet. Mas, ainda de acordo com Baudelaire, Guys desenhava de memória, com exceção de casos como a Guerra da Crimeia, onde fez presencialmente esboços rápidos para registrar rapidamente o acontecimento, para finalizá-los posteriormente. Talvez, na prática, para o ilustrador, mais importante do que evidenciar o aqui e agora da obra de arte, ainda que esse seja um valor intrínseco aos discursos documentários, seja simplesmente o esforço de ser o mais fidedigno possivel ao mesmo tempo que não confia inteiramente na memória para a reprodução de determinados momentos e situações. De acordo com Baudelaire (1996, p. 30), "estabelece-se assim um duelo entre a vontade de tudo ver, de nada esquecer, e a faculdade da memória, que adquiriu o hábito de absorver com vivacidade a cor geral e a silhueta, o arabesco do contorno". A execução da obra de Guys constitui-se em dois fatores para Baudelaire (1996, p. 31): o "esforço de memória ressurreicionista", evocadora de um passado que se presentifica, e, de outro, o "medo de não ser rápido e não captar a síntese", ou

[...] de deixar o fantasma escapar antes que sua sintese tenha sido extraida e captada; é o pavor terrivel que se apodera de todos os grandes artistas e que os faz desejar tão ardentemente apropriarem-se de todos os meios de expressão para que jamais as ordens do espírito sejam alteradas pelas hesitações da mão; para que finalmente a execução, a execução ideal se torne tão inconsciente, tão fluente quanto a digestão para o cérebro do homem sadio que acabou de jantar (BAUDELAIRE, 1996, p. 31).

Por outro lado, Cruikshank, em suas obras anteriormente mencionadas, utilizava também os dois métodos: no primeiro, é o profundo conhecedor do espaço retratado, traduzindo com fidelidade as cenas, os hábitos e o cotidiano dos londrinos, que se refletem em suas ilustrações. De outro, pelo total desconhecimento do espaço e do ambiente de Paris, apela para a pesquisa como recurso e para a memória de quem conhece e viveu aquele ambiente. Tanto a metodologia de Guys quanto as de Cruikshank foram bem-sucedidas com seus respectivos públicos. Em todas há um aspecto de preencher, completar e fabular as lacunas da memória para se chegar a uma sintese do espaço interpretado - tenha sido ele vivido ou não pelo ilustrador. A fabulação não está presente apenas nos desenhos criados a partir da reunião de informações, imagens, referências das experiências vividas de outras pessoas, mas se encontra também no próprio ato de rememorar diferentes cenas vividas do passado, como Cruikshank faz sobre o cotidiano de Londres. Assim, buscava-se a melhor forma de traduzir a sintese dos acontecimentos, mesmo que a imagem retratada não fosse produzida no momento e de acordo com a realidade vivida. A imaginação era fundamental na pintura, de acordo com Baudelaire, e segundo ele, se Courbet e Manet fracassaram, foi porque se limitavam a pintar o que viam.

Desse modo, a partir de Baudelaire, é importante legitimar tanto a imaginação quanto a presença, sendo possivel pensar em maneiras distintas de transformar a realidade em imagem documental desenhada: desenhar no aqui e agora do acontecimento; desenhar de memória a partir de um contato presencial com 
a realidade e desenhar a partir de pesquisa variada, de outros relatos e referências, sem estar no local do acontecimento. Em todas elas haveria um balanço entre a imaginação e a reprodução exata do que se vê, ambas trazidas por diferentes experiências presenciais.

Desenhar no aqui e agora do acontecimento, ao mesmo tempo que diminui os questionamentos de autenticidade proporcionados pela presença do artista, implica muitas vezes o medo de não ser rápido, descrito anteriormente por Baudelaire. Mas quase invariavelmente esse é um trabalho inacabado, que sofre mudanças posteriores e fatalmente retorna à memória e à fabulação, por melhor que estejam os primeiros traços. Sobre esse processo, Baudelaire também faz uma descrição minuciosa do processo de Guys:

G. começa por leves indicações a lápis, que apenas indicam a posição que os objetos devem ocupar no espaço. Os planos principais são indicados em seguida por tons em aguada, massas de início coloridas vagamente, levemente, porém retomadas mais tarde e carregadas sucessivamente com cores mais intensas. No último momento, o contorno dos objetos é definitivamente delineado com tinta (BAUDELAIRE, 1996, p. 32).

Baudelaire afirma, ainda, que os rápidos desenhos de G. parecem perfeitos e acabados, apesar de muitos acharem que fossem apenas esboços, ainda que ele pudesse retomar a ilustração posteriormente, enriquecendo-a com mais detalhes para seu documento. A força de seu desenho reside exatamente em certa rapidez de captar o instante e o momento do acontecimento que será retratado e que resulta no não acabado, no esboço, que imprimiriam o transitório do presente e que seriam traços da modernidade, conforme Compagnon - de certo modo como a fotografia e talvez sem apreender a maioria dos detalhes. Isso não inviabiliza, contudo, uma fabulação do ilustrador por meio de alguma complementação posterior do desenho de modo a reforçar sua intensidade.

De vez em quando G. percorre-os, folheia-os, examina-os, e depois escolhe alguns, nos quais aumenta mais ou menos a intensidade, carrega as sombras $e$ clareia progressivamente as zonas luminosas. G. dedica uma imensa importância aos fundos, que, vigorosos ou evanescentes, sempre são de uma qualidade e de uma natureza apropriadas às figuras. A gama de tons e a harmonia geral são estritamente observadas, com um gênio que provém mais do instinto do que do estudo (BAUDELAIRE, 1996, p. 33).

Interferir na intensidade, nas sombras, decidir sobre o detalhamento ou não dos fundos posteriormente, são sempre baseados na conjunção da memória com a fabulação de G. É na primeira que ele busca em sua experiência de presença no local do acontecimento os detalhes para completar a imagem. Cabe aqui a pergunta de Compagnon (2003, p. 25): “A representação do presente, a memória do presente, é ainda o presente?”. A resposta talvez esteja justamente na fabulação. Com ela o ilustrador não prioriza uma memória da imagem tal como presenciou a realidade, mas busca traduzir seu sentimento e sua interpretação diante do acontecido, ir além da própria imagem e buscar uma certa "espiritualidade" do evento. Memória e fabulação, assim, adentram ainda mais o registro documental da pretensa objetividade para uma condição de subjetividade.

$\mathrm{Na}$ contemporaneidade, é possivel adicionar mais um modo a partir do advento da fotografia, que é a utilização da referência fotográfica para fazer a ilustração. 
Essa fotografia pode ser mais um elemento da pesquisa de quem não esteve presencialmente no espaço retratado, como pode ser um elemento que contribui para o trabalho do ilustrador que viveu o espaço. No último caso, o ilustrador pode escolher abrir mão do esboço por meio de uma coleção de fotos, superar o medo de não ser rápido e captar a sintese. De fato, a descrição que Baudelaire faz dos rápidos esboços de G., feitos com o intuito de captar essa espiritualidade da informação o mais rapidamente possivel para depois detalhar, é exatamente o uso que se faz da fotografia como suporte por ilustradores ou quadrinistas documentais contemporâneos, como Joe Sacco ${ }^{8}$, ainda que o uso da fotografia seja diametralmente oposto a concepção de Baudelaire sobre a imagem não acabada. Se a fotografia não exige a arte mnemômica que Baudelaire atribui a Guys, por outro lado, quando utilizadas, as fotos funcionam como uma presentificação da memória e mais uma vez são reunidas como uma colagem em uma ilustração com o objetivo de buscar a sintese por um processo de montagem que continua a ser um exercício de fabulação. Desse modo, o real nas ilustrações parece ser, quase sempre, um misto de realidade, memória e fabulação, ainda que com estratégias distintas. A questão que se impõe é até que ponto a ilustração, pelo fato de a fabulação ser um componente importante e quase sempre inevitável, poder ser utilizada como uma matriz para um documento com a pretensão de um discurso de realidade.

\section{Deslegitimação DA ILUSTRAÇÃo}

De certa maneira, há alguma resistência nos discursos documentais contemporâneos para algumas características que definem a amplitude de métodos de criação, semelhantes ou tributárias, da ilustração documental do século XIX. É importante lembrar que, até o surgimento da fotografia e de ela se tornar o espaço preferencial de registro do real, a ilustração cumpria esse papel em gravuras e jornais ilustrados, sem qualquer restrição, fora eventuais infortúnios de pessoas públicas retratadas, alvos das críticas e ironias. A autenticidade se tornou um valor classificatório e restritivo para a ilustração quando a fotografia quebrou sua hegemonia e a empurrou para a periferia da representação visual, ocupando, assim, paulatinamente, uma função subalterna. Baudelaire tinha uma relação ambígua de atração e desprezo pela fotografia e condena uma "obsessão pelo real" da burguesia amante da fotografia, em detrimento dos valores da ilustração. Como se sabe, o alvo de Baudelaire não era especificamente a fotografia em si, mas o fato de se enfatizar o verdadeiro ao belo, o fato de evidenciar o ver em vez do imaginar. A capacidade de reproduzir o real proporcionada pela fotografia era, de acordo com o poeta francês, um limitador: Baudelaire se incomodava com uma "arte que parecia abrir mão de sua capacidade de idealização". Ao colocar a fotografia ao lado dos tradicionais ilustradores do século XIX que não se acanhavam em idealizar, fabular e montar com memória, referências e imaginação sua interpretação do real, a autenticidade paulatinamente se estabelece como um valor para a representação por meio de imagens. Mais do que isso, a capacidade de idealização da arte passa a ser um demérito para os discursos documentais, tendo em vista a ânsia ou obsessão pelo real ou pelo ver.

8 O próprio Joe Sacco afirma que, depois de dois anos visitando, pesquisando e desenhando o universo da Palestina, apesar de ter várias fotos do local como referência, pouco as utiliza e desenha tudo de memória. 
Relegada a ilustração como meio inautêntico, a imagem fotoquímica - e, depois, eletrônica e digital - ganha terreno como espaço prioritário de representação do real no século XX. Paralelamente, em diferentes mídias, a autenticidade passa a ser um parâmetro que, de formas diferentes, sistematicamente, parece reproduzir o incômodo de Baudelaire. É evidente que a fotografia, o cinema e a televisão provaram em sua história que estão longe de se restringir à obsessão pelo real e não terem capacidade de idealização, e o próprio Baudelaire depois percebe isso na fotografia. O problema que se evidencia é negar à ilustração a capacidade de reproduzir, ou melhor, de traduzir o real a partir de suas possibilidades de mesclar presença e fabulação, o ver e a imaginação, em um processo de montagem que busca não a fidedignidade da imagem, mas a síntese e uma certa 'espiritualidade' do acontecimento ou do cotidiano. Um exemplo claro reside nas teorias do cinema documentário - alguns autores (ver RAMOS, 2001) que afirmam que a imagem documental depende necessariamente da mediação de uma máquina, por esta evidenciar a presença de seu operador que se torna testemunha do fato. Por esse viés, consequentemente, essa imagem não poderia ser desenhada já que uma ilustração não garantiria a autenticidade do acontecimento por meio da figura da testemunha. Tal entendimento destrói qualquer possibilidade de um relato documental ilustrado ou pintado e aborta até mesmo outras discussões de outros meios que atrelam autenticidade à presença.

A questão da presença como um valor legitimador da realidade na cultura das mídias surge, assim, como outro limitador das iustrações documentais e fica ainda mais clara nas conhecidas estratégias jornalísticas presentes na televisão. É muito comum nos telejornais as notícias sobre um acontecimento do outro lado do mundo serem dadas por um correspondente que não se encontra no local do acontecimento, mas a meio caminho deste. Ou nem tanto. Por que algo que aconteceu no Iraque e apurado apenas por agências de notícias é informado em um telejornal por um correspondente em Nova York ou mesmo em Abu Dhabi? ${ }^{9}$. A informação é a mesma, a apuração não é local, a notícia poderia ser dada da cadeira do âncora do telejornal. Busca-se da mesma forma uma autenticidade por meio de uma percepção de presença de um correspondente que está longe do estúdio e perto do acontecimento relatado. As fronteiras geográficas pouco importam, nem mesmo o fato de ele não ter apurado no local. O que importa é passar a sensação de presença e autenticidade pelo simples fato de não estar no estúdio do telejornal.

Engana-se, contudo, quem pensa que esse tipo de crítica venha apenas de autores ou meios que privilegiam a imagem maquinica. A pesquisadora de histórias em quadrinhos Nina Mickwitz, em seu livro Documentary comics: graphic truth-telling in a skeptical age (2016) descarta a análise de quadrinhos históricos como um gênero possivel dentro dos quadrinhos documentais em detrimento de outros gêneros como as biografias e autobiografias, o jornalismo e os quadrinhos de viagem. Para a autora, a presença do ilustrador diante do acontecimento ou da realidade retratada é o que legitima e autentifica o discurso documental nas histórias em quadrinhos, o que ela define como certificado de presença. Desse modo, para a autora, histórias em quadrinhos pretensamente documen-

9 Sobre inexatidões e imprecisões em relação ao trabalho do correspondente de televisão que está e não está no local do acontecimento, assista a Control room (2014), documentário de Jehane Noujaim que trata da cobertura da Guerra do Iraque pelo viés dos correspondentes e jornalistas da Al Jazeera. 
tais que se baseiam apenas em pesquisa e fontes secundárias e terciárias não podem ser caracterizadas como discursos documentais.

São perspectivas limitadoras e com a mesma origem. A primeira impõe uma restrição relativa à obrigatoriedade da mediação da câmera como determinante, justamente porque a imagem proveniente da câmara evidencia a presença de seu operador, de acordo com Ramos, que testemunha o acontecimento. Ou seja, por essa concepção, o certificado de presença também é fundamental e definidor do documentário. Supondo que a presença seja de fato restritiva para a definição de um discurso documental, o que dizer de ilustradores que vivenciaram o acontecimento e o relato, como George Cruikshank, em Life in London, e Constantin Guys? Suas ilustrações documentais não teriam validade? Seria possivel também dizer que histórias em quadrinhos contemporâneas de autores que fazem a pesquisa in loco, como os álbuns de Joe Sacco sobre a Palestina e a Faixa de Gaza, não podem ser consideradas documentário? Depois de 100 anos de obsessão pelo real baseada em imagens instantâneas, após o surgimento e o desenvolvimento cada vez maior de mídias que se apoiam no suporte fotográfico, seja químico ou não, é necessário os autores repensarem esse pseudoespaço exclusivo de legitimidade dado pela imagem maquínica e o não reconhecimento da imagem desenhada e sua capacidade de imaginação e fabulação, retomando a acepção de Baudelaire, como um potente espaço complementar e legítimo na construção desses discursos.

Ao manter essa posição, por exemplo, o cinema entra em conflito consigo mesmo, pois nega uma de suas vertentes mais oxigenadoras e potentes, que é o documentário animado, no qual a imagem estruturalmente central no filme é, de fato, uma animação, com todas as possibilidades poéticas e criativas permitidas pela ilustração. Filmes como Ryan (2004), de Chris Reynolds; Do it yourself (2007), de Eric Ledune; e Valsa para Bashir (2008), de Ari Folman, entre tantos outros, comprovam o quanto algumas teorias documentais são datadas ao restringir e classificar o que pode ou não ser documentário ${ }^{10}$.

No entanto, no campo da mídia quadrinhos, negar as narrativas que não têm certificado de presença é negar também a constituição de qualquer história, na medida em que a presença do artista não necessariamente significa uma representação consistente do real, seja porque não desenha na hora, tendo de recuperar as imagens através de outras imagens ou outras fontes, seja porque a metodologia de apuração falha também não se exime da possibilidade de contaminações mais danosas do que as proporcionadas por pesquisas, seja porque não se deve negar e excluir a fabulação como meio. Além disso, é importante lembrar que todo o discurso histórico é uma versão e todo ato de comunicação é uma interpretação. O discurso histórico é tão duvidoso quanto qualquer outro. Nesse sentido, a análise de Peter Burke sobre o pintor John Trumbull é elucidativa:

Do mesmo modo, o pintor americano John Trumbull (1756-1843), encorajado por Thomas Jefferson, transformou no trabalho de toda a sua vida a tarefa de representar os acontecimentos mais importantes da luta pela independência. Sua pintura da Declaração de Independência, por exemplo, utilizou informação fornecida por Jefferson, que tinha participado do evento.

\footnotetext{
10 Para mais detalhes, ver Martins (2009)
} 
A respeito de outra pintura histórica de Trumbull, tem sido argumentado que "não é nem pretendia ser o relato de uma testemunha ocular": uma vez que o pintor aceitou as convenções da pintura narrativa em grande estilo, o que significava omitir qualquer coisa que pudesse diminuir a dignidade da cena, nesse caso uma batalha. Pode-se levantar o mesmo ponto a respeito das convenções literárias associadas com a doutrina da "dignidade da história", que durante muitos séculos excluiu referências às pessoas comuns (BURKE, 2004, p. 178).

Seria possivel negar as representações que Art Spiegelman faz em Maus (1980) dos campos de concentração de Birkenau onde seu pai esteve confinado? Se, de um lado, a realidade do quadrinho pode estar na mesma lógica do cinéma-vérité, em que o real e importante é o contato com o entrevistado, as histórias narradas por ele continuam sendo resultado de sua memória, com todas as suas indeterminações, e a obra continua sendo fruto de uma pesquisa, de uma montagem feita por diversas fontes, com diferentes níveis de fabulação.

No caso de Art Spiegelman (1980), os resultados e criticas muito favoráveis foram feitas por um público insuspeito, que são ex-prisioneiros do campo de concentração. Negar a pesquisa como fonte e atrelar autenticidade prioritária ou exclusivamente ao certificado de presença é reduzir as possibilidades das histórias em quadrinhos documentais e seus recursos de fabulação. É evidente que a presença do autor no espaço representado só favorece e enriquece o discurso documental, mas isso não redunda em negar outras possibilidades também não menos importantes. Mais do que isso, negar a possibilidade do quadrinho histórico denota uma pretensão equivocada de que todas as outras alternativas textuais possibilitam uma objetividade do real, pois se calcam no testemunho e este seria, em tese, inconteste.

Defendem-se aqui, portanto, a validade e a potência do que se poderia chamar, não em oposição, mas em complementaridade à proeminência da presença, de um possivel certificado de fabulação como força dos discursos documentais. A fabulação se encontra na montagem, na pesquisa, na síntese, na tradução, na busca de uma certa "espiritualidade" do acontecimento e da realidade, em suma, na própria imaginação. É o reconhecimento da validade de estratégias outras não tributárias apenas da argumentação que exige uma autenticidade como um valor da imagem documental. Algo impossivel até mesmo para a fotografia, uma vez que o enquadramento, ou a escolha do momento em que se liga e se desliga a câmera, já é por si só uma impossibilidade de reprodução da realidade. Ainda que Baudelaire falasse de outra época e com uma visão um tanto exagerada e preconceituosa da fotografia, talvez fosse necessário revalorizar a capacidade de idealização dos discursos documentais em seus mais diversos suportes midiáticos e formatos.

\section{CONSIDERAÇõES FINAIS}

A presença é um fator importante e ainda determinante em diversas mídias como valor de legitimação do discurso documental visual, ou seja, gráfico e audiovisual. Alguns autores, tanto da fotografia quanto do cinema, da televisão e mesmo das histórias em quadrinhos, parecem ainda ter dificuldade com a ausência em discursos documentais. Dessas mídias, são as histórias em quadrinhos que, aparentemente, mais se abrem para manter o caráter documental, 
agregando certificado de presença e de fabulação simultaneamente e com igual valor, talvez justamente por contar menos com décadas de uma tradição teórica que busca classificar, legitimar e, consequentemente, deslegitimar determinados tipos de conteúdos, como fazem especialmente alguns autores de cinema. De acordo com Charles Hatfield (2005, p. 128):

Essas tensões visuais ${ }^{11}$ abrem um espaço de oportunidade, de metáforas imagéticas que podem se multiplicar promiscuamente, oferecendo uma visão surreal ou extremamente subjetiva para contrabalançar a reivindicação de verdade que certifica o texto como autobiográfico. Consequentemente imagens bizarras, "irrealistas" e expressionistas podem coexistir com um relato factual escrupuloso sobre a vida de alguém. As ironias resultantes conferem uma autenticidade que é mais emocional do que literal: aquela do presente falando do passado.

Obras em quadrinhos autobiográficas, como Maus (1980), de Art Spiegelman; ou Gen (1973-1974), de Keiji Nakazawa (1939-2012), contam com relatos não presenciais ou parcialmente presenciais, além de pesquisas, para narrar fatos reais de guerras e zonas de conflito. De outro modo, trabalhos como Persepolis (2000-2003), de Marjane Satrapi (1969-); Epileptic (1996), de David B. (1959); Pílulas azuis (2008), de Frederik Peeters (1974-); e Retalhos (2003), de Craig Thompson (1975), entre outros, misturam relatos autobiográficos pessoais, presença e fabulação, trazendo a fantasia e o onírico para a realidade dos personagens. Traduzem, assim, o real pelo seu viés interpretativo, abstrato e sensitivo, concretizando em desenhos seus medos e angústias, materializando em imagens sua realidade interior e alcançando um tipo de relato documental específico, que não é impossível de alcançar pelas imagens maquínicas, mas que é, infelizmente, menos frequente. Tais histórias retomam - sem o mesmo juízo de valor explicitado na época - um pouco da capacidade da idealização valorizada no século XIX por Baudelaire. Também possibilitam o desenvolvimento de alguns modos de cinema documental apontados por Bill Nichols, como o poético e o performativo, que priorizam a subjetividade do realizador e, de alguma maneira, a revelação do eu interior como uma pertinente representação do real.

Essa não é uma qualidade exclusiva dos quadrinhos ou de algumas mídias documentais contemporâneas, pelo contrário, vem, como aqui discutido, de uma longa tradição da ilustração documental, que perdeu espaço em função dos dogmas teóricos posteriores, especialmente com o desenvolvimento de práticas e de teorias mais aguerridas do cinedocumentário, especialmente a partir da década de 1960. O potencial, a aceitação e a ampliação diária de novos títulos de quadrinhos documentais nas livrarias ${ }^{12}$ apontam não apenas para a negação desses dogmas e para a legitimação dos discursos documentais ilustrados, jogando luz em um necessário retorno para sua raiz e suas influências diretas tanto de conteúdo quanto de práticas que são os cartuns e charges editoriais dos jornais ilustrados a partir do século XVIII. Hoje, as práticas e metodologias na relação entre ilustração e acontecimento retratado continuam as mesmas daquela época, com pequenas exceções.

\footnotetext{
11 Hatfield refere-se à oposição entre o abstrato e o discursivo (a alavra), de um lado, e de outroo concreto e o visual (a imagem).

12 Em algumas livrarias e especialmente comic shops em diversos países, existe a separação nas prateleiras para quadrinhos históricos, reportagens, biografias e autobiografias.
} 
Poderíamos aproximar a pesquisa e o discurso documental de Life in Paris, de George Cruikshank, por exemplo, dos de Fax de Sarajevo, de Joe Kubert (1926-2012), que o autor criou a partir de relatos da família de Ervin Rustemagić enviados por fax para os Estados Unidos direto da Bósnia, além de outras pesquisas, sem também nunca ter pisado ou vivido o conflito de Sarajevo. Life in London, por sua vez, poderia se aproximar dos relatos do cotidiano feitos por Robert Crumb (1943-) e Harvey Pekar (1939-2010), que conheciam intimamente o ambiente retratado, aproximando o leitor das nuanças desse espaço. Entretanto, os relatos ilustrados da Guerra da Crimeia de Constantin Guys encontram uma correspondência óbvia na metodologia de Joe Sacco, tanto pelo fato de viajar, vivenciar o acontecimento, entrevistar testemunhas ${ }^{13}$ e dizer o que viu quanto por fabular e utilizar a memória para completar e preencher os desenhos até chegarem não a uma transposição - impossivel - do real, mas a uma espiritualidade do acontecimento a partir de sua subjetividade. Outros autores, como James Gillray e Honoré Daumier, ao retratarem o caricato, distorcendo e fabulando, apresentam as mesmas ferramentas usadas por quase todas as histórias em quadrinhos documentais contemporâneas, que não veem problema na distorção como modo de chegar a uma interpretação mais sensitiva do real.

Depois de mencionar inúmeros ilustradores europeus, não se pode esquecer também do trabalho do ítalo-brasileiro Angelo Agostini (1843-1910), que no século XIX publicou em periódicos como O Mosquito, O Cabrião, A Vida Fluminense, O Tico-Tico, O Malho, a Revista Illustrada e em inúmeras outras, fazendo aguçadas críticas à sociedade e ao poder vigente com um forte engajamento contra a escravatura. O mais interessante de Agostini é o fato de ele ser o mesmo observador do cotidiano que os outros, mas já inserido dentro de uma prática gráfica e narrativa bem semelhante aos quadrinhos, apesar da falta de enquadramentos mais fechados e do balão em suas histórias. As aventuras de Nhô Quim, em 1869, e Zé Caipora, em 1883, eram crônicas da vida da época no Brasil, especialmente no Rio de Janeiro, encaixando-se em perfil semelhante apontado por Baudelaire de um observador da modernidade - ainda que a modernidade no Brasil, naquela época, estivesse longe de acontecer.

Desse modo, observando tanto Agostini no Brasil quanto os ilustradores ingleses e franceses discutidos neste artigo, evidencia-se que as práticas dos quadrinhos documentais contemporâneos, com algumas exceções trazidas pela fotografia e pelo desenvolvimento das artes gráficas e do mercado editorial no decorrer do tempo, reativam as mesmas práticas da ilustração dos séculos XVIII e XIX. Mais do que isso, evidencia-se a importância da fabulação, da memória e da subjetividade na constituição não apenas da ilustração, mas de todos os discursos documentais. Privar-se dessas estratégias para narrar por meio de imagens de outra ordem, que não condizem com os parâmetros estabelecidos de autenticidade para alguns, é abrir mão de um potente e vigoroso espaço de comunicação. Amarrar-se a tabus restritivos do que pode ou não ser considerado autêntico limita e desvaloriza algumas das narrativas documentais mais instigantes e inovadoras, sejam elas nos quadrinhos, no cinema, na televisão, na fotografia ou na ilustração. Negar as práticas dessas ilustrações como relatos documentais pelo fato de a imagem não ser maquínica ou pela ausência de um

13 A estratégia de entrevistar testemunhas de acontecimentos já era, de acordo com Burke (2004, p. 185), uma metodologia encontrada na pintura do século XIX de Horace Vernet e Henry Barker. 
certificado de presença é abrir mão, no mínimo, não apenas de uma extensa documentação, mas também do único registro possivel de uma época que inventariou hábitos, costumes, utensílios, vestuário, espaços urbanos e acontecimentos. É, no fim, negar a própria história.

\section{Authenticity, PRESENCE AND FABUlation in DOCUMENTAL ILlUSTRATion}

Abstract: Through the analysis of the illustrators George Cruikshank (1782-1878) and Constantin Guys (1802-1892), this paper intent to discuss the tradition of documental illustration in the XVIII and XIX centuries. These authors already deal in their practices with important and common characteristics in the stressing of contemporary documental discourses, notably comic books; like presence, fabulation and autenticity issues. Authors such as Charles Baudelaire (18211867), Peter Burke (1937-) and Antoine Compagnon (1950-) will be discussed.

Keywords: Illustration. Fabulation. Presence.

\section{REFERÊNCIAS}

ACKERMAN, A. Eisenstein et Daumier. des affinités électives. Paris: Armand Colin, 2014.

AGOSTINI, A. As aventuras de Nhô Quim \& Zé Caipora: os primeiros quadrinhos brasileiros 1869-1883. Brasília: Senado Federal, Conselho Editorial, 2002.

BAUDELAIRE, C. Sobre a modernidade. Rio de Janeiro: Paz e Terra, 1996.

BURKE, P. Testemunha ocular: história e imagem. Bauru: Edusc, 2004.

CHUTE, H. Disaster drawn: visual witness, comics and documentary form. Cambridge: Belknap Press, 2016.

COMOLLI, J. L. Machines of the visible. In: DE LAURETIS, T.; HEATH, S. (org.). The cinematic apparatus. New York: St Martin's Press, 1980. p. 120-142.

COMPAGNON, A. Os cinco paradoxos da modernidade. Belo Horizonte: UFMG, 2003.

CRUIKSHANK, G.; CRUIKSHANK, R.; EGAN, P. Life in London. London: Paternoster-Row, 1821.

CRUIKSHANK, G.; AREY, D. Life in Paris. London: John Fairburn, 1822.

DAVID, B. Epileptic. New York: Pantheon Books, 2005.

EVANS, H. The man who drew the drunkard's daughter. the life and art of George Cruikshank 1792-1878. London: Frederick Muller Limited, 1978.

HATFIELD, C. Alternative Comics: an emerging literature. Mississippi: University of Mississippi Press, 2005.

KUBERT, J. Fax de Sarajevo. São Paulo: Via Leitura, 2016.

MARTINS, I. Documentário animado: muito além da técnica e da tecnologia. Interstícios, Rio de Janeiro, v. 1, n. 1, p. 103-114, 2009.

MICKWITZ, N. Documentary comics: graphic truth-telling in a skeptical age. Hampshire: Palgrave Macmillan, 2016. 
NAKAZAWA, K. Gen, pés descalços: uma história de Hiroshima. São Paulo: Conrad, 1999.

PETER, F. Pílulas Azuis. São Paulo: Nemo: 2015.

RAMOS, F. O que é documentário? In: RAMOS, F. P.; CATANI, A. (org.). Estudos de Cinema Socine 2000. Porto Alegre: Sulina, 2001. p. 192-207.

SACCO, J. Área de Segurança Gorazde: a Guerra na Bósnia Oriental 1992-1995. São Paulo: Conrad, 2001.

SACCO, J. Palestina. São Paulo: Conrad, 2000.

SACCO, J. Notas sobre Gaza. São Paulo: Companhia das Letras, 2010.

SATRAPI, M. Persepolis 1. São Paulo: Companhia das Letras, 2004.

SATRAPI, M. Persepolis 2. São Paulo: Companhia das Letras, 2005.

SATRAPI, M. Persepolis 3. São Paulo: Companhia das Letras, 2006.

SATRAPI, M. Persepolis 4. São Paulo: Companhia das Letras, 2007.

SPIEGELMAN, A. Maus. New York: Pantheon Books, 1991.

THOMPSON, C. Retalhos. São Paulo: Companhia das Letras, 2009.

Recebido em 9 de agosto de 2018.

Aprovado em 23 de março de 2019. 